\title{
Diffusion-controlled synthesis of Cu-based catalysts for the Rochow reaction
}

\author{
Hezhi Liu ${ }^{1,2 \dagger}$, Jing $\mathrm{Li}^{2 \dagger}$, Yongjun $\mathrm{Ji}^{2^{*}}$, Zailei Zhang ${ }^{2}$, Xueguang Wang ${ }^{1^{*}}$, Ziyi Zhong ${ }^{3}$ and Fabing $\mathrm{Su}^{2,4^{*}}$
}

\begin{abstract}
The properties of materials are strongly dependent on their structures. The diffusion effect is a main kinetic factor that can be used to regulate the growth and structure of materials. In this work, we developed a systematic and feasible strategy to synthesize $\mathrm{Cu}_{2} \mathrm{O}$ solid spheres and hexahedrons by controlling the diffusion coefficients. These $\mathrm{Cu}_{2} \mathrm{O}$ products can be successively transformed into corresponding $\mathrm{Cu}$ hollow spheres and hexahedrons as well as $\mathrm{CuO}$ porous spheres and hexahedrons by controlling hydrogen diffusion in hydrazine hydrate solution and controlling oxygen diffusion in air, respectively. The formation of these transformations was also discussed in detail. Tested for Rochow reaction, the as-prepared $\mathrm{Cu}_{2} \mathrm{O}$ solid and $\mathrm{CuO}$ porous spheres exhibit higher dimethyldichlorosilane selectivity and $\mathrm{Si}$ conversion than $\mathrm{Cu}$ hollow spheres, which is attributed to the active sites for $\mathrm{CH}_{3} \mathrm{Cl}$ adsorption formed in $\mathrm{Cu}_{x} \mathrm{Si}$ phase after the removal of oxygen atoms in $\mathrm{Cu}_{2} \mathrm{O}$ and $\mathrm{CuO}$ in the formation of dimethylchlorosilane. The present work not only develops a feasible method for preparing well shape-defined $\mathrm{Cu}_{2} \mathrm{O}$ solid spheres and hexahedrons but also clarifies the respective roles of $\mathrm{Cu}, \mathrm{Cu}_{2} \mathrm{O}$ and $\mathrm{CuO}$ in dimethyldichlorosilane synthesis via Rochow reaction.
\end{abstract}

Keywords: cuprous oxide, hollow spheres, porous spheres, surface oxygen vacancies, Rochow reaction

\section{INTRODUCTION}

Controllable synthesis of materials with well-defined shapes has attracted immense research interest in recent years, due to the unique morphology-dependent physical and chemical properties [1-4]. The diffusion effect in controllable synthesis is a main kinetic factor for regulating materials structure in materials science fields
$[5,6]$. Very recently, various materials with controlled shapes such as snow-like vaterite [5] and silver dendritic [7] have been successfully synthesized by controlling chemical diffusion and reaction kinetics. Cuprous oxide $\left(\mathrm{Cu}_{2} \mathrm{O}\right)$, an important metal oxide that possesses unique optical and electrical properties [8], has been widely applied in various fields such as catalysis $[9,10]$, sensors [11], and energy conversion and storage [12]. In the last several years, the controllable synthesis of $\mathrm{Cu}_{2} \mathrm{O}$ microand nano-sized crystals with a vast array of architectures, including core-shell $\mathrm{Cu}_{2} \mathrm{O}$ spheres [13], hollow $\mathrm{Cu}_{2} \mathrm{O}$ spheres [14], and porous $\mathrm{Cu}_{2} \mathrm{O}$ spheres [15] has been achieved using electrodeposition method, thermal relaxation method, sonochemical method, vacuum evaporation method, $\gamma$-irradiation method, and liquid-phase reduction method [16-18]. Additionally, metallic copper $(\mathrm{Cu})$ and copper oxide $(\mathrm{CuO})$ with various structures have also received intense attention, as they can be used in catalysis, sensors, and electronics [19-26]. However, the aforementioned synthesis approaches often involve the use of surfactants, template, and high temperature and pressure to obtain morphology-controllable $\mathrm{Cu}_{2} \mathrm{O}$ structures, which undoubtedly increases the synthesis cost and thus limits their large-scale production. Therefore, it is highly desired to develop a feasible and green method to fabricate shape-controlled $\mathrm{Cu}_{2} \mathrm{O}$ via adjusting diffusion parameters.

Rochow reaction is the so-called direct process employed in industry to produce methylchlorosilanes, in which silicon $(\mathrm{Si})$ reacts with chloromethane $\left(\mathrm{CH}_{3} \mathrm{Cl}\right)$ over the Cu-based catalysts [27]. Metallic $\mathrm{Cu}$ [28] and copper compounds such as $\mathrm{Cu}_{2} \mathrm{O}$ [29], $\mathrm{CuO}$ [30], $\mathrm{CuCl}$ [31], and $\mathrm{Cu}-\mathrm{Cu}_{2} \mathrm{O}-\mathrm{CuO}$ composites [32] are known to be

\footnotetext{
${ }^{1}$ State Key Laboratory of Advanced Special Steel, School of Materials Science and Engineering, Shanghai University, Shanghai 200072, China

${ }^{2}$ State Key Laboratory of Multiphase Complex Systems, Institute of Process Engineering, Chinese Academy of Sciences, Beijing 100190, China

${ }^{3}$ Institute of Chemical and Engineering Sciences, Agency for Science, Technology and Research (A*STAR), Singapore 627833, Singapore

${ }^{4}$ Institute of Industrial Chemistry and Energy Technology, Shenyang University of Chemical Technology, Shenyang 110142, China

These authors contributed equally to this work.

* Corresponding authors (emails: yjji@ipe.ac.cn (Ji Y); wxg228@shu.edu.cn (Wang X); fbsu@ipe.ac.cn (Su F))
} 
catalytically active for this reaction with the assistance of some promoters. The selective synthesis of dimethyldichlorosilane $\left(\left(\mathrm{CH}_{3}\right)_{2} \mathrm{SiCl}_{2}, \mathrm{M} 2\right)$ from this reaction is most desirable in the organosilane industry. Therefore, many efforts have been made to develop efficient $\mathrm{Cu}$-based catalysts to improve M2 selectivity and yield $[33,34]$. Previously, we explored a series of model catalysts for Rochow reaction, and observed that $\mathrm{Cu}_{2} \mathrm{O}$ and $\mathrm{CuO}$ were more active than metallic $\mathrm{Cu}$ [28-30], but the true role of oxygen species was not clear yet because of the high complexity of the reaction and the irregularity in morphology of the catalyst particles. It is reported that the surface oxygen vacancies are the most relevant surface defects in metal oxides, which may assist in band bending and subsequent electron-hole pair separation in various applications, especially in catalysis [35-37]. Also, first quantum-mechanical and density functional theory studies have revealed that surface oxygen vacancies can impact the function of $\mathrm{Cu}$ atoms $[38,39]$. It is expected that a systematic comparison of the catalytic activity between $\mathrm{Cu}, \mathrm{Cu}_{2} \mathrm{O}$ and $\mathrm{CuO}$ catalysts with the same shape will simply the issue and possibly provide better understanding to the role of oxygen species and the catalytic mechanism through clarifying the role of the surface oxygen vacancies.

Here, we report a simple well-controlled synthesis of $\mathrm{Cu}_{2} \mathrm{O}$ solid spheres and hexahedrons by controlling the diffusion coefficients, including adjusting solvents, reactant concentration, and temperature. Subsequently, the $\mathrm{Cu}$ hollow spheres and $\mathrm{CuO}$ porous spheres are prepared by diffusion-controlled reduction of $\mathrm{Cu}_{2} \mathrm{O}$ with hydrazine hydrate solution and oxidation of $\mathrm{Cu}_{2} \mathrm{O}$ in air. Compared with the hollow $\mathrm{Cu}$ sphere catalyst used for $\mathrm{M} 2$ synthesis via Rochow reaction, the $\mathrm{Cu}_{2} \mathrm{O}$ solid spheres and $\mathrm{CuO}$ porous spheres show enhanced M2 selectivity and Si conversion. The role of oxygen species and the reaction mechanism were discussed accordingly.

\section{EXPERIMENTAL}

\section{Materials synthesis}

\section{Synthesis of $\mathrm{Cu}_{2} \mathrm{O}$ solid spheres}

The synthesis conditions used in this work are summerized in Table S1. In a typical synthesis, $2.0 \mathrm{~g}$ of copper acetate $\left(\mathrm{Cu}\left(\mathrm{CH}_{3} \mathrm{COO}\right)_{2} \cdot \mathrm{H}_{2} \mathrm{O}\right.$, analytical reagent $(\mathrm{AR})$, Sinopharm Chemical Reagent Co., Ltd) was dissolved in a mixture of $40.0 \mathrm{~mL}$ deionized water and $40.0 \mathrm{~mL}$ methanol. Upon heating to $70^{\circ} \mathrm{C}, 2.8 \mathrm{~g}$ of sodium hydroxide (NaOH, AR, Sinopharm Chemical Reagent Co., Ltd) and
2.4 g of glucose $\left(\mathrm{C}_{6} \mathrm{H}_{12} \mathrm{O}_{6} \cdot \mathrm{H}_{2} \mathrm{O}\right.$, AR, Sinopharm Chemical Reagent Co., Ltd) were added into the solution with stirring. The mixture was stirred for another $60 \mathrm{~min}$ at $70^{\circ} \mathrm{C}$, and then cooled to room temperature. The resulting precipitate was collected by centrifugation, washed with distilled water and absolute ethanol for several times, and finally dried under vacuum at $80^{\circ} \mathrm{C}$ for $24 \mathrm{~h}$.

\section{Synthesis of $\mathrm{CuO}$ porous spheres}

The obtained $\mathrm{Cu}_{2} \mathrm{O}$ solid spheres were oxidized in air to prepare $\mathrm{CuO}$ porous spheres. Typically, $0.5 \mathrm{~g}$ of $\mathrm{Cu}_{2} \mathrm{O}$ solid spheres was placed in a square crucible, which was then put in a corundum tube in a tube furnace. The sample was oxidized in air $\left(50.0 \mathrm{~mL} \mathrm{~min}{ }^{-1}\right)$ at $350{ }^{\circ} \mathrm{C}$ for $6 \mathrm{~h}$, then cooled to room temperature naturally.

\section{Synthesis of $\mathrm{Cu}$ hollow spheres}

The obtained $\mathrm{Cu}_{2} \mathrm{O}$ solid spheres were reduced with hydrazine hydrate solution to prepare $\mathrm{Cu}$ hollow spheres. Typically, $0.5 \mathrm{~g}$ of $\mathrm{Cu}_{2} \mathrm{O}$ solid spheres was placed in a beaker with $50 \mathrm{~mL}$ of deionized water, followed by the addition of $0.5 \mathrm{~mL}$ of hydrazine hydrate ( $80 \mathrm{wt} . \%)$. The reaction was carried out at room temperature for $12 \mathrm{~h}$. The resulting precipitate was collected by centrifugation, washed with distilled water and absolute ethanol for several times, and finally dried under vacuum at $80^{\circ} \mathrm{C}$ for $24 \mathrm{~h}$.

\section{Materials characterization}

X-ray diffraction (XRD) were recorded on a PANalytical $\mathrm{X}^{\prime}$ Pert PRO MPD using the $\mathrm{Cu} \mathrm{Ka}$ radiation $(\lambda=$ $1.5418 \AA$ ). The microscopic feature of the samples was characterized by a field-emission scanning electron microscopy (FESEM) with energy-dispersive X-ray spectrometer (EDX) (JSM-7001F, JEOL, Tokyo, Japan) and transmission electron microscopy (TEM) (JEM-2010F, JEOL, Tokyo, Japan) operated at $200 \mathrm{kV}$. Thermal gravimetric (TG) analysis was carried out on an EXSTAR TG/DTA 6300 (Seiko Instruments, Japan) at a heating rate of $2^{\circ} \mathrm{C} \mathrm{min}^{-1}$ in air $\left(200 \mathrm{~mL} \mathrm{~min}^{-1}\right)$ from 30 to $900^{\circ} \mathrm{C}$. $\mathrm{H}_{2}$-temperature programmed reduction $\left(\mathrm{H}_{2}-\mathrm{TPR}\right)$ measurements were carried out on an automated chemisorption analyzer (ChemBET pulsar TPR/TPD, Quantachrome). $0.10 \mathrm{~g}$ of $\mathrm{Cu}_{2} \mathrm{O}$ particles was initially loaded in a quartz U-tube. Prior to the measurement, the sample was degassed at $200^{\circ} \mathrm{C}$ for $4 \mathrm{~h}$ under helium. When the temperature was dropped to $20^{\circ} \mathrm{C}$, the gas was switched to 9.9 vol.\% $\mathrm{H}_{2} /$ Ar. Finally, the sample was heated from 20 to $500^{\circ} \mathrm{C}$ under 9.9 vol. $\% \mathrm{H}_{2} / \mathrm{Ar}$ with a flow rate of $30 \mathrm{~mL} \mathrm{~min}^{-1}$. 


\section{Catalytic measurement}

The evaluation of catalyst was carried out with a typical fixed-bed reactor [33]. $10.0 \mathrm{~g}$ of Si powder (20-50 mesh, provided by Jiangsu Hongda New Material Co., Ltd.) and $0.5 \mathrm{~g}$ of $\mathrm{Cu}_{2} \mathrm{O}$, together with $0.05 \mathrm{~g}$ of zinc $(\mathrm{Zn}, \mathrm{AR}, \mathrm{Si}-$ nopharm Chemical Reagent Co., Ltd) as the promoter, were ground homogeneously to form a contact mass, which was then loaded into a glass reactor. The reactor system was purged with purified $\mathrm{N}_{2}$ for $0.5 \mathrm{~h}$ followed by heating to $325^{\circ} \mathrm{C}$ within $1 \mathrm{~h}$ under a $\mathrm{N}_{2}$ flow rate of $25 \mathrm{~mL} \mathrm{~min}^{-1}$. Subsequently, $\mathrm{N}_{2}$ was turned off, and $\mathrm{CH}_{3} \mathrm{Cl}$ gas with a flow rate of $25 \mathrm{~mL} \mathrm{~min}^{-1}$ was introduced into the reactor to react with $\mathrm{Si}$ followed by heating to $325^{\circ} \mathrm{C}$. After a given period of $24 \mathrm{~h}$, the reaction was stopped. The gas products were cooled into a liquid phase with the circulator bath controlled at $-5^{\circ} \mathrm{C}$ by a programmable thermal circulator (GDH series, Ningbo Xinzhi Biological Technology Co., LTD). The products in the liquid solution were quantitative analyzed by gas chromatograph (GC-7890A, Agilent Technologies) equipped with a KB201 capillary column $(60 \mathrm{~m})$ and a thermal conductivity detector (TCD). Gas chromatography-mass spectrometry (GC-MS, QP2010, Shimadzu) was used for identification of the products, which contained methyltricholorsilane $\left(\mathrm{CH}_{3} \mathrm{SiCl}_{3}, \mathrm{M1}\right)$, dimethyldichlorosilane $\left(\left(\mathrm{CH}_{3}\right)_{2} \mathrm{SiCl}_{2}\right.$, $\mathrm{M} 2)$, trimethylchlorosilane $\left(\left(\mathrm{CH}_{3}\right)_{3} \mathrm{SiCl}, \mathrm{M} 3\right)$, methyldichlorosilane $\left(\mathrm{CH}_{3} \mathrm{SiHCl}_{2}, \mathrm{M} 1 \mathrm{H}\right)$, dimethylchlorosilane $\left(\left(\mathrm{CH}_{3}\right)_{2} \mathrm{SiHCl}, \mathrm{M} 2 \mathrm{H}\right)$, low boiler (LB) and high boiler (HB). The selectivity was calculated by the peak area ratio (in mass percentage; peak area calibrated with response factor). The Si conversion was determined by the ratio of mass difference of Si powder (before and after the reaction) and the mass of $\mathrm{Si}$ (before the reaction) (Formula 1).

$$
\mathrm{Cu}^{2+}+2 \mathrm{OH}^{-} \rightarrow \mathrm{Cu}(\mathrm{OH})_{2},
$$

Here $m_{\mathrm{Si} \text {,before }}$ and $m_{\mathrm{Si} \text {,after }}$ represent the mass of $\mathrm{Si}$ powder before and after the reaction, respectively. The amount of unreacted $\mathrm{Si}$ after the reaction was measured by inductively coupled plasma optical emission spectrometer (ICP-OES). The calibration was done with commercial multi-element standard solutions. Prior to ICPOES analysis, the waste contact masses were completely dissolved with $\mathrm{HF} / \mathrm{HNO}_{3}$ solution and evaporated to almost dryness. Then, the concentrated solutions were diluted with a $2 \% \mathrm{HNO}_{3}$ solution. Si element was measured for three times to determine standard deviations.

\section{RESULTS AND DISCUSSION}

Previous reports have demonstrated that the diffusion rate and reaction parameters are the most important factors in the synthesis materials with well-defined shape $[5,7]$. The solvent, reactant concentration, and reaction temperature have strong impact on the diffusion coefficients of reactant, whereas the reaction order and reducing agent affect the reaction processes. Therefore, to obtain well-defined $\mathrm{Cu}_{2} \mathrm{O}$ particles with uniform morphology and size, we systematically investigated the effects of diffusion and reaction parameters, as shown in Fig. S1.

\section{Diffusion-controlled synthesis of $\mathrm{Cu}_{2} \mathrm{O}$ hexahedron and $\mathrm{Cu}_{2} \mathrm{O}$ spheres}

\section{Effect of the concentration of precursor solution and the} solvents

Fig. 1a shows the XRD patterns of $\mathrm{Cu}_{2} \mathrm{O}$ hexahedrons and $\mathrm{Cu}_{2} \mathrm{O}$ spheres obtained in pure water (S1) and a methanol/water mixture (S2), respectively. In both cases, the diffraction peaks at $29.5^{\circ}, 36.3^{\circ}, 42.2^{\circ}, 61.3^{\circ}$, and $73.5^{\circ}$ are observed and indexed to the lattice planes of (110), (111), (200), (220), and (311) of cubic $\mathrm{Cu}_{2} \mathrm{O}$ (JCPDS No. 00005-0667), respectively. Using Debye-Scherrer formula based on the (111) peak at $36.3^{\circ}$, the calculated average crystal size of $\mathrm{Cu}_{2} \mathrm{O}$ is 35.6 and $42.6 \mathrm{~nm}$ for the $\mathrm{Cu}_{2} \mathrm{O}$ hexahedrons and $\mathrm{Cu}_{2} \mathrm{O}$ spheres, respectively. The SEM image reveals that $\mathrm{S} 1$ (Fig. 1b) is composed of only regular and dense hexahedrons with smooth surface and diameter of about $1-2 \mu \mathrm{m}$. As the concentration of precursor solution decreases, a mixture of $\mathrm{Cu}_{2} \mathrm{O}$ hexahedrons and spheres with a diameter of about $0.5-2 \mu \mathrm{m}$ is obtained (S3, Fig. 1c). From the inset of Fig. 1c, it is clearly seen that the hexahedrons have cavernous surfaces. However, with increasing the solution component concentration, a large portion of non-uniform $\mathrm{Cu}_{2} \mathrm{O}$ particles is formed (Fig. S2). When methanol is added in preparing $\mathrm{S} 1$, well-dispersed $\mathrm{Cu}_{2} \mathrm{O}$ solid spheres (S2) with a diameter of about $1-3 \mu \mathrm{m}$ are obtained (Fig. 1d-f). In the cases of adding ethanol (S6), glycol (S7) and glycerol (S8), non-uniform $\mathrm{Cu}_{2} \mathrm{O}$ spheres mixed with smaller irregular nanoparticles were synthesized (Fig. S3). In addition, the influence of component concentration of the prepared solution in mixed methanol/water solvent was also investigated and the results are shown in Fig. S4.

According to Wilke and Chang Equation, the order of diffusion coefficients in various solvents is as follows: water $>$ methanol + water $>$ ethanol + water $>$ glycol + water $>$ glycerol + water $[40,41]$. The above results suggest the diffusion coefficients have a strong influence on the morphology of $\mathrm{Cu}_{2} \mathrm{O}$ particles, and the uniform and pure $\mathrm{Cu}_{2} \mathrm{O}$ solid hexahedron and spheres can be prepared 

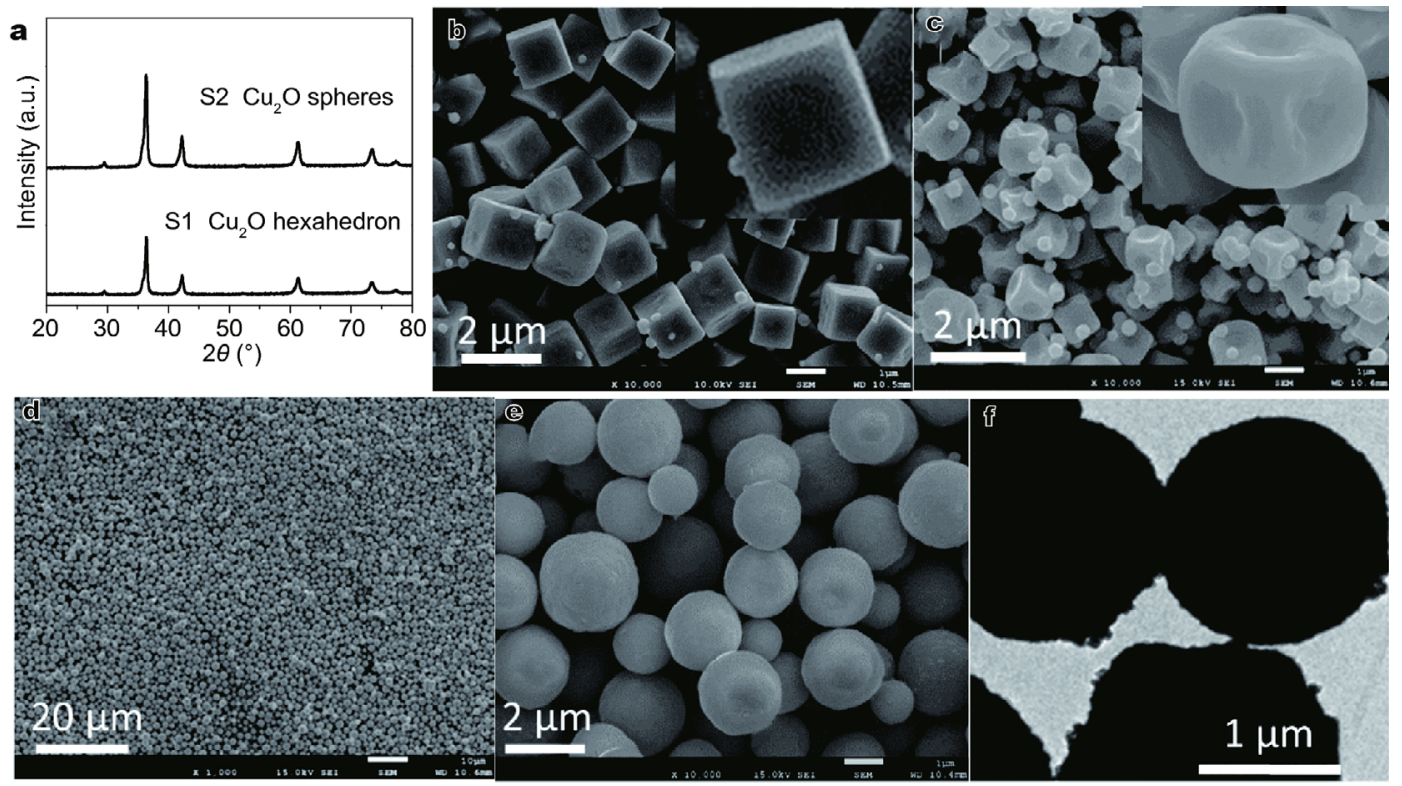

Figure 1 XRD patterns of $\mathrm{Cu}_{2} \mathrm{O}$ hexahedron and $\mathrm{Cu}_{2} \mathrm{O}$ spheres (a), SEM images of $\mathrm{Cu}_{2} \mathrm{O}$ particles obtained in different solvents: water (S1, S3) (b, c), water + methanol (S2) (d, e), and TEM image of $\mathrm{Cu}_{2} \mathrm{O}$ spheres (S2) (f).

only with proper diffusion coefficients. In the synthesis process of $\mathrm{Cu}_{2} \mathrm{O}$, the reactant and the initially formed small nanoclusters and nanoparticles can diffuse quickly in water, but it becomes slower in methanol, ethanol, glycol, and glycerol gradually. Thus, the $\mathrm{Cu}_{2} \mathrm{O}$ morphology evolution should be the result of the different diffusion coefficients obtained by changing the concentration of the prepared solution and reaction solvent, which influence the ion transfer rate in solution.

To further confirm the influence of diffusion coefficients on $\mathrm{Cu}_{2} \mathrm{O}$ particles forming, we performed a series of control experiments by varying the solvent ratios. As mentined above, when pure water is used as the solvent (S3), only are $\mathrm{Cu}_{2} \mathrm{O}$ hexahedrons with a diameter of about $1 \mu \mathrm{m}$ obtained (Fig. 1c). After adding $10 \mathrm{~mL}$ of methanol ( $S 9$, water:methanol $=70: 10$ ), there is no obvious change in the size of the $\mathrm{Cu}_{2} \mathrm{O}$ products compared with $\mathrm{S} 2$, but the shape becomes irregular and some $\mathrm{Cu}_{2} \mathrm{O}$ spheres appear (Fig. 2a). With the addition of more methanol (S10, water:methanol $=60: 20 ; S 8$, water:methanol $=$ 50:30), non-uniform and irregular $\mathrm{Cu}_{2} \mathrm{O}$ particles are formed (Fig. 2b, c); meanwhile, more particles become the spherical structure. Upon further adding methanol to $50 \mathrm{~mL}$ (S12, water:methanol $=30: 50$ ), the obtained products are composed of porous spheres with a diameter of about 1-2 $\mu \mathrm{m}$ (Fig. $2 \mathrm{~d}$ ). The diffusion coefficient of methanol/water mixture decreases first with addition of the methanol in the concentration of $0-40 \mathrm{~mol} . \%$, but in-

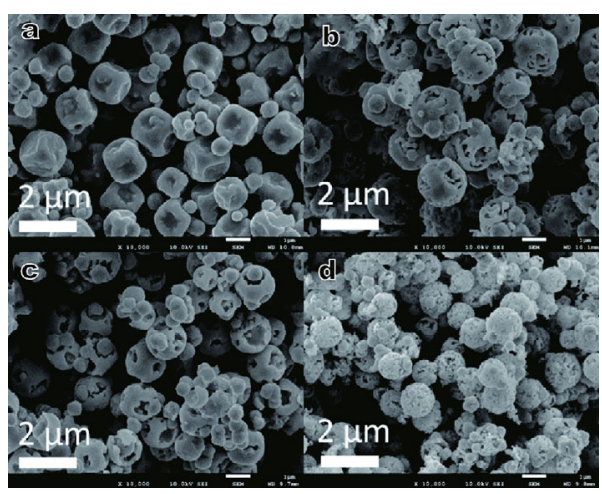

Figure 2 SEM images of the products obtained at different volume ratios of water : methanol: $70: 10$ (S9) (a), $60: 20$ (S10) (b), $50: 30$ (S11) (c), and $30: 50(\mathrm{~S} 12)(\mathrm{d})$.

creases again with further increase of methanol (40-100 mol.\%). For example, the diffusion coefficient for pure water is $2.275 \times 10^{-9} \mathrm{~m}^{2} \mathrm{~s}^{-1}, 10 \%$ of methanol is $1.656 \times$ $10^{-9} \mathrm{~m}^{2} \mathrm{~s}^{-1}, 30 \%$ of methanol is $1.273 \times 10^{-9} \mathrm{~m}^{2} \mathrm{~s}^{-1}, 50 \%$ of methanol is $1.341 \times 10^{-9} \mathrm{~m}^{2} \mathrm{~s}^{-1}$, and $70 \%$ of methanol is $1.566 \times 10^{-9} \mathrm{~m}^{2} \mathrm{~s}^{-1}$ at $298 \mathrm{~K}[42,43]$. Accordingly, the $\mathrm{Cu}_{2} \mathrm{O}$ hexahedrons become spheres with the decrease of diffusion coefficient, then porous spheres with the increase of diffusion coefficient.

Effect of the reaction temperature

Fig. 3 shows the SEM images of $\mathrm{Cu}_{2} \mathrm{O}$ particles obtained 
at different temperatures. It can be seen that sample S13 obtained at $50^{\circ} \mathrm{C}$ has a spherical morphology with a size distribution of $1-3 \mu \mathrm{m}$ (Fig. 3a), and the surface of spheres is smooth. Similar results are observed for the samples obtained at 60 and $70^{\circ} \mathrm{C}(\mathrm{S} 14$ and S2) (Figs $3 \mathrm{~b}$ and $1 \mathrm{e}$ ), which are all $\mathrm{Cu}_{2} \mathrm{O}$ spheres with relatively uniform morphology. However, when the temperature reaches 80 and $90^{\circ} \mathrm{C}$, the obtained sample S15 and S16 exhibit a non-uniform particle size distribution as compared to those of S2, S13, and S14 (Fig. 3c, d). It should be pointed out that at these temperatures, the products are composed of mainly $\mathrm{Cu}_{2} \mathrm{O}$ particles and small portion of $\mathrm{Cu}$ particles according to the XRD results (Fig. S5). Hence, the reaction temperature between 50 and $70^{\circ} \mathrm{C}$ should be suitable for the preparation of homogeneous $\mathrm{Cu}_{2} \mathrm{O}$ spheres. The diffusion coefficients of methanol/ water mixtures rises gradually with the increase of the temperature, e.g., the diffusion coefficients of water is $1.298 \times 10^{-9} \mathrm{~m}^{2} \mathrm{~s}^{-1}$ at $278 \mathrm{~K}$ and $2.275 \times 10^{-9} \mathrm{~m}^{2} \mathrm{~s}^{-1}$ at $298 \mathrm{~K}$, while that of $50 \%$ of methanol $+50 \%$ of water is $0.741 \times 10^{-9} \mathrm{~m}^{2} \mathrm{~s}^{-1}$ at $278 \mathrm{~K}$ and $1.341 \times 10^{-9} \mathrm{~m}^{2} \mathrm{~s}^{-1}$ at $298 \mathrm{~K}$ $[42,43]$. Similarly, the diffusion coefficients of the solute in methanol + water mixtures should also rise with the increase of reaction temperature.

Effect of adding reactant sequence and different reducing agents

The effect of reactant addition sequence and different reducing agents were investigated. The formation of $\mathrm{Cu}_{2}$ $\mathrm{O}$ spheres involves the formation of $\mathrm{CuO}$ nanoparticles and their reduction, as shown in Equations 1-3:

$$
\begin{aligned}
& \mathrm{Cu}^{2+}+2 \mathrm{OH}^{-} \rightarrow \mathrm{Cu}(\mathrm{OH})_{2}, \\
& \mathrm{Cu}(\mathrm{OH})_{2} \rightarrow \mathrm{CuO}+\mathrm{H}_{2} \mathrm{O}, \\
& 2 \mathrm{CuO}+\mathrm{C}_{6} \mathrm{H}_{12} \mathrm{O}_{6}+\mathrm{OH}^{-} \rightarrow \mathrm{Cu}_{2} \mathrm{O}+\mathrm{C}_{6} \mathrm{H}_{11} \mathrm{O}_{7}^{-}+\mathrm{H}_{2} \mathrm{O} .
\end{aligned}
$$

Compared with the uniform $\mathrm{Cu}_{2} \mathrm{O}$ spheres obtained in the case of glucose (Fig. 4a) (S2), smaller $\mathrm{Cu}$ particles are directly prepared using ascorbic acid (Fig. 4b) (S17) and

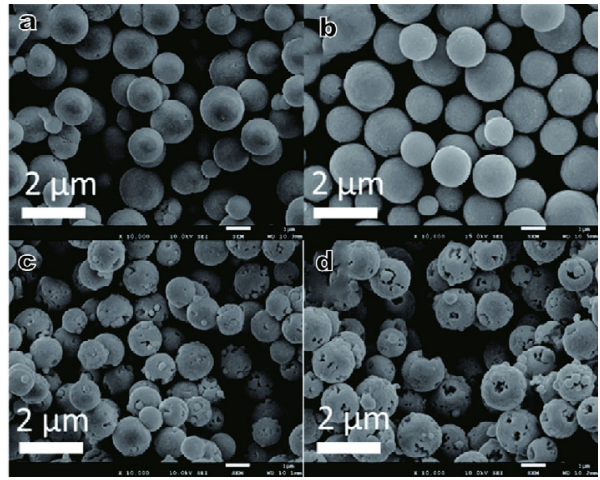

Figure $3 \mathrm{SEM}$ images of $\mathrm{Cu}_{2} \mathrm{O}$ particles obtained at different reaction temperature: $50^{\circ} \mathrm{C}(\mathrm{S} 13)(\mathrm{a}), 60^{\circ} \mathrm{C}(\mathrm{S} 14)(\mathrm{b}), \mathrm{Cu}$ and $\mathrm{Cu}_{2} \mathrm{O}$ particles obtained at $80^{\circ} \mathrm{C}(\mathrm{S} 15)(\mathrm{c}), 90^{\circ} \mathrm{C}(\mathrm{S} 16)(\mathrm{d})$.

hydrazine hydrate (Fig. 4c) (S18) as the reducing agent. Three solvents (pure water, water + methanol, and water + ethanol) were used to study the influence of the reaction processes on the $\mathrm{Cu}_{2} \mathrm{O}$ shape by reactant addition sequence. When $\mathrm{Cu}\left(\mathrm{CH}_{3} \mathrm{COO}\right)_{2}$ and $\mathrm{C}_{6} \mathrm{H}_{12} \mathrm{O}_{6}$ were first added, $\mathrm{Cu}_{2} \mathrm{O}$ nanoparticles were initially formed but without formation of the black $\mathrm{CuO}$ nanoparticles which was revealed from the evolution of the solution color. After adding $\mathrm{NaOH}$, the fast formed black $\mathrm{CuO}$ nanoparticles were quickly reduced to form non-uniform $\mathrm{Cu}_{2} \mathrm{O}$ particles in pure water (S19) (Fig. S6a), in water + methanol (S20) (Fig. S6b), and in water + ethanol (S21) (Fig. S6c). When $\mathrm{C}_{6} \mathrm{H}_{12} \mathrm{O}_{6}$ and $\mathrm{NaOH}$ were first added, none of products was obtained. After adding $\mathrm{Cu}\left(\mathrm{CH}_{3}\right.$ $\mathrm{COO})_{2}$, the black $\mathrm{CuO}$ nanoparticles were quickly formed, followed by a rapid reduction of $\mathrm{CuO}$ to $\mathrm{Cu}_{2} \mathrm{O}$ nanoparticles and further self-assembly to non-uniform $\mathrm{Cu}_{2} \mathrm{O}$ microparticles in pure water (S22) (Fig. S6d), in water + methanol (S23) (Fig. S6e) and in water + ethanol (S24) (Fig. S6f). All of these six samples are $\mathrm{Cu}_{2} \mathrm{O}$ particles according to the XRD patterns (not shown here). Thus, the reaction processes have strong influence on the shape of $\mathrm{Cu}_{2} \mathrm{O}$ products.
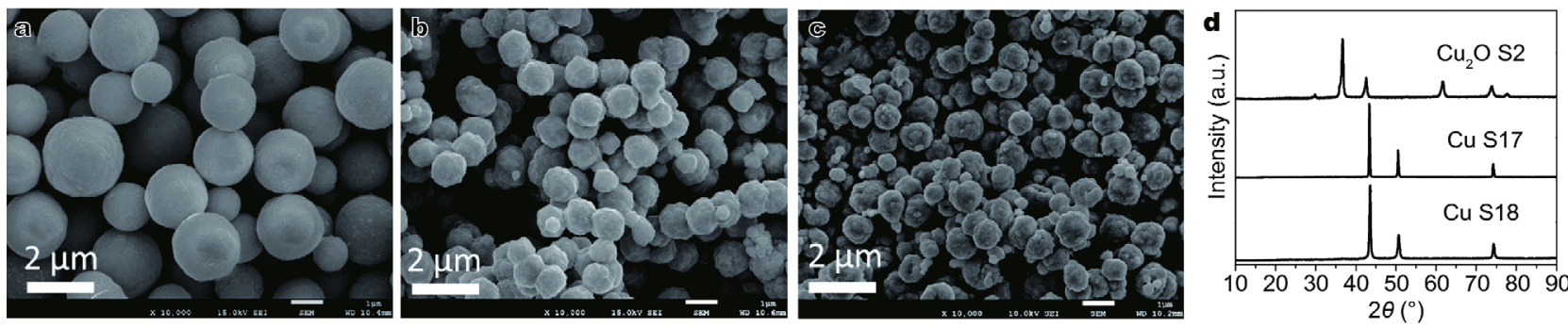

Figure 4 SEM images of the obtained $\mathrm{Cu}_{2} \mathrm{O}$ particles using glucose as reducing agent (S2) (a), the obtained Cu particles using ascorbic acid (S17) (b), and hydrazine hydrate (S18) (c) as reducing agent, and XRD patterns of these samples in water and methanol (d). 

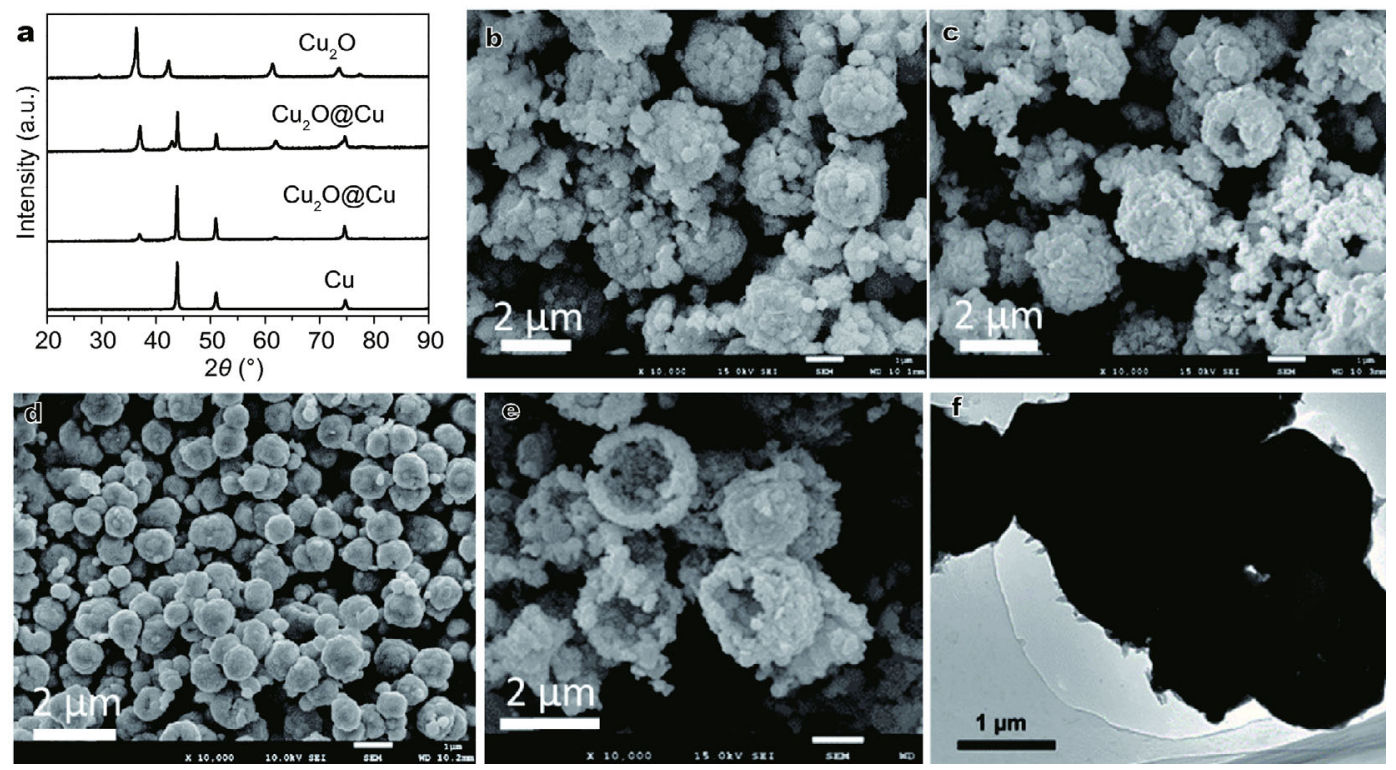

Figure 5 XRD patterns of the samples (a), SEM images of $\mathrm{Cu}_{2} \mathrm{O} @ \mathrm{Cu}$ core-shell spheres obtained by reduction with hydrazine hydrate for $4 \mathrm{~h}$ (b) and $8 \mathrm{~h}$ (c), $\mathrm{Cu}$ hollow spheres obtained by reduction with hydrazine hydrate for $12 \mathrm{~h}\left(\mathrm{~d}\right.$ and e), TEM images of $\mathrm{Cu}_{2} \mathrm{O} @ \mathrm{Cu}$ core-shell spheres obtained by reduction with hydrazine hydrate for $8 \mathrm{~h}(\mathrm{f})$.

Diffusion-controlled synthesis of $\mathrm{Cu}$ hollow and $\mathrm{CuO}$ porous spheres as well as $\mathrm{Cu}$ and $\mathrm{CuO}$ hexahedrons The formation of $\mathrm{Cu}$ hollow spheres and $\mathrm{CuO}$ porous spheres is illustrated in Equations 5 and 6, respectively.

$$
\begin{gathered}
2 \mathrm{Cu}_{2} \mathrm{O}+\mathrm{N}_{2} \mathrm{H}_{4} \rightarrow 4 \mathrm{Cu}+\mathrm{N}_{2}+2 \mathrm{H}_{2} \mathrm{O}, \\
2 \mathrm{Cu}_{2} \mathrm{O}+\mathrm{O}_{2} \rightarrow 4 \mathrm{CuO} .
\end{gathered}
$$

When the $\mathrm{Cu}_{2} \mathrm{O}$ solid spheres are reduced with hydrazine hydrate for 4 and $8 \mathrm{~h}$, the $\mathrm{Cu}_{2} \mathrm{O} @ \mathrm{Cu}$ core-shell spheres are obtained (Fig. 5b, c). SEM-EDX line-scan analysis (Fig. S7a) shows the presence of both $\mathrm{Cu}$ and $\mathrm{O}$ elements with an atomic ratio of 90:10 for $\mathrm{Cu}_{2} \mathrm{O} @ \mathrm{Cu}$ core-shell spheres. By comparing the $\mathrm{Cu}$ and $\mathrm{O}$ elements atomic ratio, which is 65:35 in $\mathrm{Cu}_{2} \mathrm{O}$ spheres (Fig. S7b), part of $\mathrm{Cu}_{2} \mathrm{O}$ is reduced to $\mathrm{Cu}$ in the $\mathrm{Cu}_{2} \mathrm{O} @ \mathrm{Cu}$ core-shell spheres, indicating the formation of a structure containing a $\mathrm{Cu}_{2} \mathrm{O}$ core and a $\mathrm{Cu}$ shell. From the XRD patterns of Fig. 5a, the $\mathrm{Cu}$ content in $\mathrm{Cu}_{2} \mathrm{O} @ \mathrm{Cu}$ core-shell spheres is rising with the increase of the reduction time. When the reduction time is prolonged to $12 \mathrm{~h}$, all of the $\mathrm{Cu}_{2} \mathrm{O}$ solid spheres become $\mathrm{Cu}$ hollow spheres, as verified by both SEM images (Fig. 5d, e) and XRD patterns (Fig. 5a). The TEM image (Fig. 5f) further confirms that the $\mathrm{Cu}_{2} \mathrm{O} @ \mathrm{Cu}$ core-shell structure was formed when $\mathrm{Cu}_{2} \mathrm{O}$ was reduced for $8 \mathrm{~h}$. The formation of hollow $\mathrm{Cu}$ spheres may be related to the generation and release of $\mathrm{N}_{2}$ molecules.

The porous $\mathrm{CuO}$ spheres were prepared by oxidizing the obtained $\mathrm{Cu}_{2} \mathrm{O}$ spheres in air. Fig. 6a shows the XRD patterns of the $\mathrm{Cu}_{2} \mathrm{O}$ spheres, $\mathrm{Cu}_{2} \mathrm{O} @ \mathrm{CuO}$ core-shell spheres and $\mathrm{CuO}$ porous spheres. When the $\mathrm{Cu}_{2} \mathrm{O}$ spheres were oxidized in air at $350^{\circ} \mathrm{C}$ for $2 \mathrm{~h}$, the $\mathrm{Cu}_{2} \mathrm{O}$ @ $\mathrm{CuO}$ core-shell spheres were formed, as shown in Fig. $6 \mathrm{~b}, \mathrm{c}$. Further increasing the oxidation time to $4 \mathrm{~h}$, uniformly core-shell structured $\mathrm{Cu}_{2} \mathrm{O} @ \mathrm{CuO}$ spheres were obtained (Fig. 6d, f). SEM-EDX spectrum and line scan show the presence of both $\mathrm{Cu}$ and $\mathrm{O}$ elements with an atomic ratio of 54:46 in $\mathrm{Cu}_{2} \mathrm{O} @ \mathrm{CuO}$ core-shell spheres, indicating that some of $\mathrm{Cu}_{2} \mathrm{O}$ spheres were oxidized to $\mathrm{CuO}$ forming $\mathrm{Cu}_{2} \mathrm{O} @ \mathrm{CuO}$ core-shell structure (Fig. S7c). Finally, the regular porous $\mathrm{CuO}$ spheres were prepared when $\mathrm{Cu}_{2} \mathrm{O}$ spheres were oxidized for $6 \mathrm{~h}$, as shown in Fig. $6 \mathrm{~g}, \mathrm{~h}$. The observed lattice spacing of $0.25 \mathrm{~nm}$ corresponds to the (111) plane of monoclinic $\mathrm{CuO}$, as shown in high resolution TEM (HRTEM) image of Fig. 6i. The formation of porous $\mathrm{CuO}$ spheres can be attributed to the air forming void space among $\mathrm{CuO}$ nanoparticles. Additionally, the $\mathrm{Cu}$ and $\mathrm{CuO}$ hexahedron were also successfully obtained by reduction and oxidation of $\mathrm{Cu}_{2} \mathrm{O}$ hexahedron (Fig. S8).

The formation process of $\mathrm{Cu}_{2} \mathrm{O}$ solid spheres, $\mathrm{Cu}$ hollow spheres and $\mathrm{CuO}$ porous spheres

According to the above observations, the formation of $\mathrm{Cu}_{2} \mathrm{O} @ \mathrm{Cu}$ core-shell spheres and $\mathrm{Cu}$ hollow spheres can be illustarted in Fig. 7a, which involves dissociation of $\mathrm{N}_{2} \mathrm{H}_{4}$, removal of $\mathrm{O}$ atoms from $\mathrm{Cu}_{2} \mathrm{O}$ and generation of 

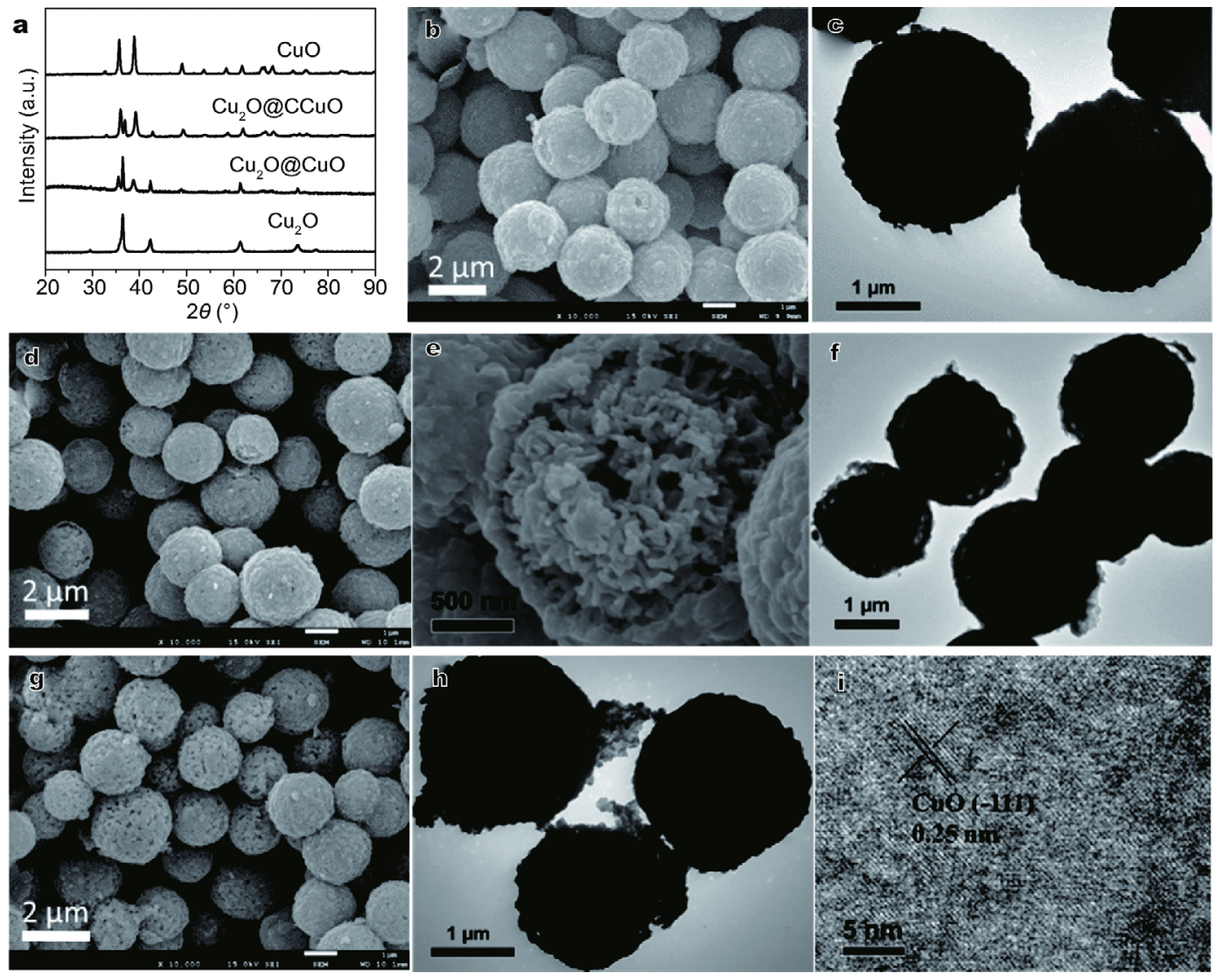

Figure 6 XRD patterns of the samples (a), SEM images of $\mathrm{Cu}_{2} \mathrm{O} @ \mathrm{CuO}$ core-shell spheres obtained by oxidation in air at $350^{\circ} \mathrm{C}$ for $2 \mathrm{~h}(\mathrm{~b})$, and $4 \mathrm{~h}(\mathrm{~d}$ and e), $\mathrm{CuO}$ porous spheres obtained by oxidation in air at $350^{\circ} \mathrm{C}$ for $6 \mathrm{~h}(\mathrm{~g})$, TEM images of $\mathrm{Cu}_{2} \mathrm{O} @ \mathrm{CuO}$ core-shell spheres obtained by oxidation in

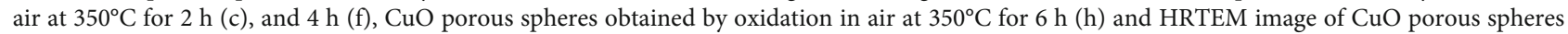
(i).

$\mathrm{H}_{2} \mathrm{O}$ via $\mathrm{H}$ atom diffusion. At the initial stage of the reduction, the surface of the $\mathrm{Cu}_{2} \mathrm{O}$ crystals contacts with $\mathrm{N}_{2} \mathrm{H}_{4}$ to form lattice defects, then $\mathrm{Cu}_{2} \mathrm{O}$ reacts with $\mathrm{H}$ atoms in $\mathrm{N}_{2} \mathrm{H}_{4}$ to form $\mathrm{N}_{2}$ and $\mathrm{H}_{2} \mathrm{O}$ [44]. The dissociated $\mathrm{H}$ atoms from $\mathrm{N}_{2} \mathrm{H}_{4}$ further penetrate into the $\mathrm{Cu}_{2} \mathrm{O}$ lattices, the inner $\mathrm{Cu}_{2} \mathrm{O}$ diffuses out to react with $\mathrm{N}_{2} \mathrm{H}_{4}$; the driving force for out-diffusion originates from concentration gradient. This involves a solid-phase diffusion process, which is the so-called Kirkendall effect [45]. Ultimately, $\mathrm{Cu}_{2} \mathrm{O}$ is converted to $\mathrm{Cu}$ completely forming $\mathrm{Cu}$ hollow spheres. Hence, by tuning the reduction time, it is able to control the content of $\mathrm{Cu}_{2} \mathrm{O}$ and $\mathrm{Cu}$, and the interior structure of the $\mathrm{Cu}_{2} \mathrm{O} @ \mathrm{Cu}$ core-shell spheres. In the oxidation processes (Fig. 7b), the diffusion of oxygen occurs at the $\mathrm{Cu}_{2} \mathrm{O}$-oxygen interface to form $\mathrm{CuO}$ developing from the surface to interior. At the beginning of oxidation, the surfaces of $\mathrm{Cu}_{2} \mathrm{O}$ spheres are firstly oxidized to $\mathrm{CuO}$. The continuous oxidation could be extended from the outer surface to the interior space. Finally, porous $\mathrm{CuO}$ spheres resulting from Kirkendall effect are formed until all $\mathrm{Cu}_{2} \mathrm{O}$ are consumed and completely transformed to $\mathrm{CuO}$ by reacting with oxygen [46-48]. $\mathrm{Cu}_{2} \mathrm{O}$ oxidation can be also contributed to lattice diffusion. Thus, by tuning the oxidation time, it is able to control the content of both $\mathrm{Cu}_{2} \mathrm{O}$ and $\mathrm{CuO}$ as well in the $\mathrm{Cu}_{2} \mathrm{O} @ \mathrm{CuO}$ core-shell spheres. In a word, the variation of the products in hollow or porous structure can be attributed to Kirkendall effect, the gas $\left(\mathrm{N}_{2}\right.$ and $\left.\mathrm{O}_{2}\right)$ void and the atoms diffusion effect. The diffusion of atoms in different compositions occurs where the void is present, leaving room for other atoms to move in.

\section{Catalytic properties of $\mathrm{Cu}, \mathrm{Cu}_{2} \mathrm{O}$, and $\mathrm{CuO}$ as $\mathrm{Cu}$-based} catalysts for the Rochow reaction

Fig. 8 and Table S2 show the catalytic performance of $\mathrm{Cu}$, $\mathrm{Cu}_{2} \mathrm{O}, \mathrm{CuO}$ spheres and hexahedrons as $\mathrm{Cu}$-based catalysts for Rochow reaction at $325^{\circ} \mathrm{C}$. It can be seen that $\mathrm{CuO}$ and $\mathrm{Cu}_{2} \mathrm{O}$ catalysts exhibit a $\mathrm{Si}$ conversion, which is $30.6 \%$ for $\mathrm{CuO}$ spheres, $35.4 \%$ for $\mathrm{CuO}$ hexahedrons, 23.2\% for $\mathrm{Cu}_{2} \mathrm{O}$ spheres and $29.4 \%$ for $\mathrm{Cu}_{2} \mathrm{O}$ hexahe- 


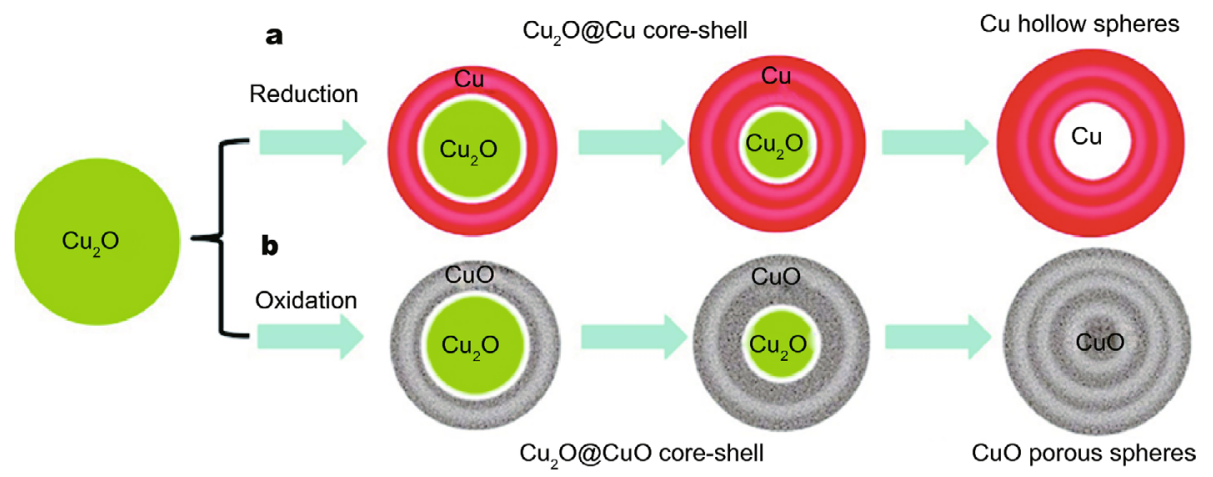

Figure 7 Schematic illustration of the reduction and oxidation processes of $\mathrm{Cu}_{2} \mathrm{O}$ spheres to form $\mathrm{Cu}$ hollow spheres and $\mathrm{CuO}$ porous spheres.

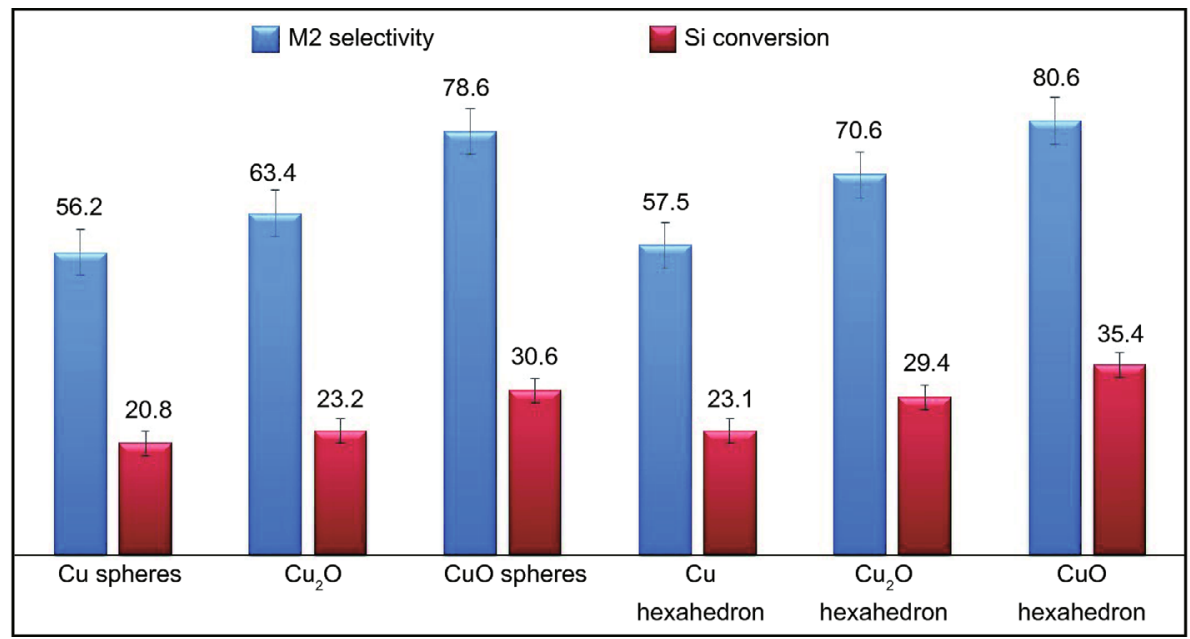

Figure 8 Selectivity for $\mathrm{M} 2$ and conversion of $\mathrm{Si}$ for $\mathrm{Cu}, \mathrm{Cu}_{2} \mathrm{O}, \mathrm{CuO}$ spheres and hexahedrons for Rochow reaction. Error bars, standard deviation of triplicated wells. The catalytic measurements were independently repeated three times to obtain three M2 selectivity and Si conversion for each catalyst.

drons, higher than those of $\mathrm{Cu}$ spheres (20.8\%) and $\mathrm{Cu}$ hexahedron (23.1\%). More importantly, $\mathrm{CuO}$ and $\mathrm{Cu}_{2} \mathrm{O}$ show higher M2 selectivity as well, which is $78.6 \%$ for $\mathrm{CuO}$ spheres, $80.6 \%$ for $\mathrm{CuO}$ hexahedron, $63.4 \%$ for $\mathrm{Cu}_{2} \mathrm{O}$ spheres and $70.6 \%$ for $\mathrm{Cu}_{2} \mathrm{O}$ hexahedron, as compared to those of $\mathrm{Cu}$ spheres (56.2\%) and $\mathrm{Cu}$ hexahedron (57.5\%). As we know, a high M2 selectivity and yield are highly desirable in the organosilane industry. Our results demonstrate that the synthesized $\mathrm{CuO}$ and $\mathrm{Cu}_{2} \mathrm{O}$ catalysts possess much better catalytic activity for M2 synthesis than $\mathrm{Cu}$ catalysts with a similar morphology. It should be pointed out that the $\mathrm{Cu}_{2} \mathrm{O}$ hexahedrons show much higher dimethyldichlorosilane selectivity and Si conversion than $\mathrm{Cu}_{2} \mathrm{O}$ spheres, which is probably because the former has stronger reducibility. This has been verified by the $\mathrm{H}_{2}$-TPR characterization, which shows that the maximum reduction peak for $\mathrm{Cu}_{2} \mathrm{O}$ hexahedron is lower than that for $\mathrm{Cu}_{2} \mathrm{O}$ spheres (Fig. S9).

The measured XRD patterns of the contact masses using $\mathrm{Cu}$ hollow spheres, $\mathrm{Cu}_{2} \mathrm{O}$ solid spheres, and $\mathrm{CuO}$ porous spheres as catalysts after a reaction of $24 \mathrm{~h}$ are shown in Fig. 9a. It can be seen that, the reacted contact masses are composed of $\mathrm{Si}$ and $\mathrm{Cu}$, but of no $\mathrm{Cu}_{2} \mathrm{O}$ and $\mathrm{CuO}$ species due to the reaction of $\mathrm{CH}_{3} \mathrm{Cl}$ with the lattice oxygen from $\mathrm{Cu}_{2} \mathrm{O}$ and $\mathrm{CuO}$ forming $\mathrm{Cu}$ in the induction period [33]. An enlargement of the XRD patterns in the range of $40^{\circ}-50^{\circ}$ (Fig. 9b) shows the presence of $\mathrm{Cu}_{x} \mathrm{Si}$ species in all the reacted contact masses, and higher intensities of $\mathrm{Cu}_{x} \mathrm{Si}$ are observed in the cases of $\mathrm{CuO}+\mathrm{Si}$ and $\mathrm{Cu}_{2} \mathrm{O}+\mathrm{Si}$ than that in $\mathrm{Cu}+\mathrm{Si}$, suggesting that pure $\mathrm{CuO}$ and $\mathrm{Cu}_{2} \mathrm{O}$ catalysts are more active in generating $\mathrm{Cu}_{x} \mathrm{Si}$ than the pure $\mathrm{Cu}$ catalyst. In Rochow reaction, the $\mathrm{Cu}_{x} \mathrm{Si}$ species are regarded as the real catalytic active species, on which, M2 is selectively produced [49]. Ele- 

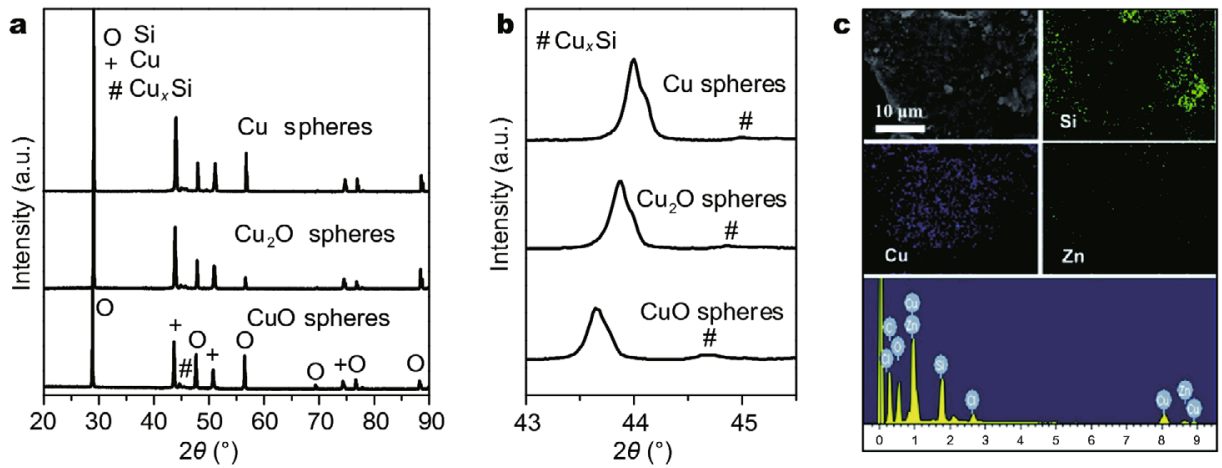

Figure $9 \mathrm{XRD}$ patterns of reacted contact masses for $\mathrm{Cu}$ hollow spheres, $\mathrm{Cu}_{2} \mathrm{O}$ solid spheres, CuO porous sphere catalysts after reaction of $24 \mathrm{~h}$ (a), and SEM image, elemental mapping images of $\mathrm{Si}, \mathrm{Cu}, \mathrm{Zn}$, and SEM-EDX spectra of contact masses using CuO porous sphere catalyst (b).

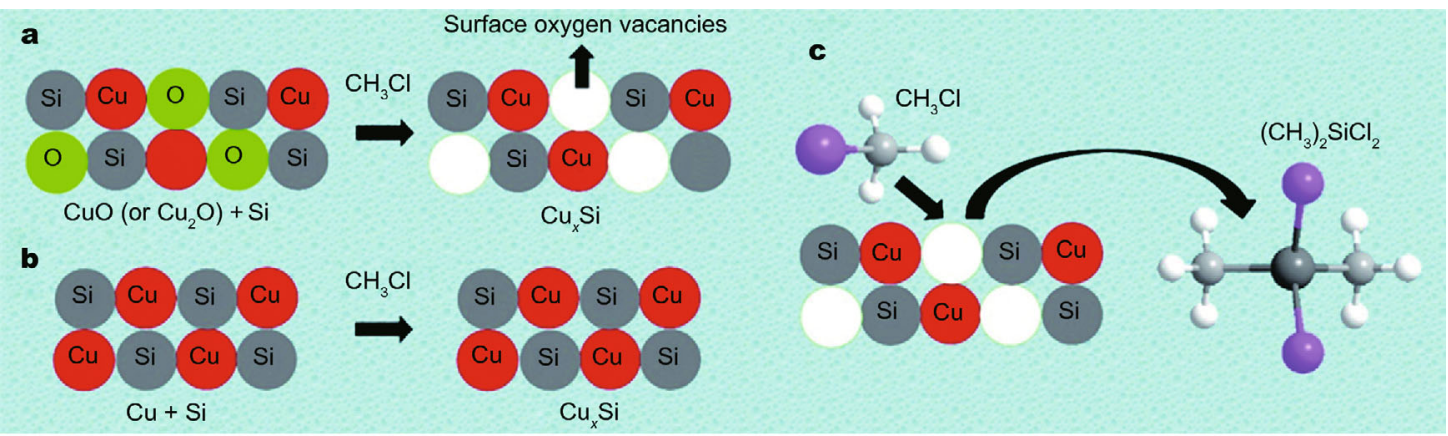

Figure 10 The illustration of the catalytic mechanism using $\mathrm{CuO}\left(\right.$ or $\mathrm{Cu}_{2} \mathrm{O}$ ) forming surface oxygen vacancies and $\mathrm{Cu}_{x} \mathrm{Si}(\mathrm{a})$ and $\mathrm{using} \mathrm{Cu}$ forming $\mathrm{Cu}_{x} \mathrm{Si}$ without surface oxygen vacancies (b), and the formation processes of $\left(\mathrm{CH}_{3}\right)_{2} \mathrm{SiCl}_{2}$ on high active surface oxygen vacancies (c).

mental mapping images of $\mathrm{Si}, \mathrm{Cu}, \mathrm{Zn}$, and SEM-EDX spectra of contact masses using $\mathrm{CuO}$ porous spheres as the catalyst indicate the uniform distribution of the elements $\mathrm{Si}, \mathrm{Cu}$, and $\mathrm{Zn}$ on the reaction interface, as shown in Fig. 9c.

Defects such as oxygen vacancies play a crucial role in the surface properties of transition metal oxides. As we know, the loss of an oxygen atom from $\mathrm{Cu}_{2} \mathrm{O}$ and $\mathrm{CuO}$ generates an oxygen vacancy. Surface oxygen vacancies are the most relevant surface defects in metal oxides, and they participate in a large number of chemical reactions $[35,50]$. Although the exact mechanism of Rochow reaction over $\mathrm{Cu}$-based catalysts is still unclear, previous studies have shown that $\mathrm{CH}_{3} \mathrm{Cl}$ first adsorbs on the surface to form $\mathrm{Cu}_{x} \mathrm{Si}$ active phase, then reacts with $\mathrm{Si}$ atoms to form M2 $[26,30,33,49]$. Based on the catalytic results and the aforementioned analysis, a mechanism of surface oxygen vacancies as important catalytic sites for Rochow reaction is first proposed and illustrated in Fig. 10. The reaction of $\mathrm{CH}_{3} \mathrm{Cl}$ with the lattice oxygen from $\mathrm{Cu}_{2} \mathrm{O}$ and $\mathrm{CuO}$ generates surface oxygen vacancies and $\mathrm{Cu}_{x} \mathrm{Si}$ when using $\mathrm{Cu}_{2} \mathrm{O}$ and $\mathrm{CuO}$ catalysts (Fig. 10a). However, only
$\mathrm{Cu}_{x} \mathrm{Si}$ phase without surface oxygen vacancies is formed when using $\mathrm{Cu}$ catalyst (Fig. 10b). The diffusion of a $\mathrm{CH}_{3} \mathrm{Cl}$ molecule is typically rapid and in equilibrium. Thus, the highly active surface oxygen vacancies in $\mathrm{Cu}_{x} \mathrm{Si}$ are preferential adsorption sites for $\mathrm{CH}_{3} \mathrm{Cl}$ molecules $[33,51,52]$. Upon adsorption on the $\mathrm{Cu}_{x} \mathrm{Si}$ surface, the $\mathrm{CH}_{3} \mathrm{Cl}$ molecule can readily dissociate into electronegative $\mathrm{Cl}^{-}$and electropositive $\mathrm{CH}_{3}^{+}$, which are then drawn by the high active surface oxygen vacancies to the reaction sites [24,30]. Subsequently, the electropositive $\mathrm{Cu}^{+}$in $\mathrm{Cu}_{x} \mathrm{Si}$ absorbs electronegative $\mathrm{Cl}^{-}$, while electronegative $\mathrm{Si}^{-}$in $\mathrm{Cu}_{x} \mathrm{Si}$ absorbs electropositive $\mathrm{CH}_{3}^{+}$, and finally, the electronegative $\mathrm{Cl}^{-}$transfers to and combine with Si forming M2 via a exothermic process (Fig. 10c).

\section{CONCLUSIONS}

In summary, we demonstrated a diffusion-controlled synthesis route to prepare well-defined $\mathrm{Cu}_{2} \mathrm{O}$ solid spheres by controlling the diffusion coefficients through adjusting the solvents, reactant concentration, and reaction temperature. Subsequently, the Cu hollow spheres and $\mathrm{CuO}$ porous spheres were prepared by controlled 
hydrogen diffusion reduction of $\mathrm{Cu}_{2} \mathrm{O}$ in hydrazine hydrate solution and controlled oxygen diffusion oxidation of $\mathrm{Cu}_{2} \mathrm{O}$ in air, respectively. As compared to the $\mathrm{Cu}$ hollow spheres, both the $\mathrm{Cu}_{2} \mathrm{O}$ solid and $\mathrm{CuO}$ porous spheres can greatly enhance the M2 selectivity and Si conversion in Rochow reaction, which is possibly due to the generated highly active surface oxygen vacancies in the $\mathrm{Cu}_{x} \mathrm{Si}$ phase. The work not only demonstrates a new approach to the development of novel $\mathrm{Cu}$-based catalysts with high activity, but also provides deep understanding of the roles of $\mathrm{Cu}, \mathrm{Cu}_{2} \mathrm{O}$ and $\mathrm{CuO}$ in Rochow reaction.

\section{Received 16 August 2017; accepted 20 September 2017; published online 7 November 2017}

1 Yin Y, Alivisatos A. Colloidal nanocrystal synthesis and the organic-inorganic interface. Nature, 2005, 437: 664-670

2 Wu Y, Wang D, Li Y. Understanding of the major reactions in solution synthesis of functional nanomaterials. Sci China Mater, 2016, 59: 938-996

3 Liang Y, Shang L, Bian T, et al. Shape-controlled synthesis of polyhedral 50 -facet $\mathrm{Cu}_{2} \mathrm{O}$ microcrystals with high-index facets. CrystEngComm, 2012, 14: 4431-4436

4 Shang L, Liang Y, Li M, et al. "Naked" magnetically recyclable mesoporous $\mathrm{Au}-\gamma-\mathrm{Fe}_{2} \mathrm{O}_{3}$ nanocrystal clusters: a highly integrated catalyst system. Adv Funct Mater, 2017, 27: 1606215

5 Wang H, Han Y, Li J. Dominant role of compromise between diffusion and reaction in the formation of snow-shaped vaterite. Cryst Growth Des, 2013, 13: 1820-1825

6 Liu B, Wang Q, Yu S, et al. Architecture engineering toward highly active palladium integrated titanium dioxide yolk-double-shell nanoreactor for catalytic applications. Nanoscale, 2014, 6: 1188711897

7 Liu W, Yang T, Li C, et al. Regulating silver morphology via electrochemical reaction. CrystEngComm, 2015, 17: 6014-6022

8 Wang Q, Shang Y, Yu L, et al. Facet-dependent $\mathrm{Cu}_{2} \mathrm{O}$ nanocrystals in manipulating alignment of liquid crystals and photomechanical behaviors. Nano Res, 2016, 9: 2581-2589

9 Huang WC, Lyu LM, Yang YC, et al. Synthesis of $\mathrm{Cu}_{2} \mathrm{O}$ nanocrystals from cubic to rhombic dodecahedral structures and their comparative photocatalytic activity. J Am Chem Soc, 2012, 134: 1261-1267

10 Pan $\mathrm{L}$, Zou JJ, Zhang $\mathrm{T}$, et al. $\mathrm{Cu}_{2} \mathrm{O}$ film via hydrothermal redox approach: morphology and photocatalytic performance. J Phys Chem C, 2014, 118: 16335-16343

11 Deng S, Tjoa V, Fan H, et al. Reduced graphene oxide conjugated $\mathrm{Cu}_{2} \mathrm{O}$ nanowire mesocrystals for high-performance $\mathrm{NO}_{2}$ gas sensor. J Am Chem Soc, 2012, 134: 4905-4917

12 Chen W, Li L, Peng Q, et al. Polyol synthesis and chemical conversion of $\mathrm{Cu}_{2} \mathrm{O}$ nanospheres. Nano Res, 2012, 5: 320-326

13 Geng B, Liu J, Zhao Y, et al. A room-temperature chemical route to homogeneous core-shell $\mathrm{Cu}_{2} \mathrm{O}$ structures and their application in biosensors. CrystEngComm, 2011, 13: 697-701

$14 \mathrm{Xu} \mathrm{H}$, Wang W. Template synthesis of multishelled $\mathrm{Cu}_{2} \mathrm{O}$ hollow spheres with a single-crystalline shell wall. Angew Chem Int Ed, 2007, 46: 1489-1492

15 Zhang Z, Che H, Wang Y, et al. Facile synthesis of mesoporous $\mathrm{Cu}_{2} \mathrm{O}$ microspheres with improved catalytic property for di- methyldichlorosilane synthesis. Ind Eng Chem Res, 2012, 51: 1264-1274

16 Lu C, Qi L, Yang J, et al. One-pot synthesis of octahedral $\mathrm{Cu}_{2} \mathrm{O}$ nanocages via a catalytic solution route. Adv Mater, 2005, 17: 2562-2567

17 Yin $\mathrm{M}, \mathrm{Wu} \mathrm{CK}$, Lou Y, et al. Copper oxide nanocrystals. J Am Chem Soc, 2005, 127: 9506-9511

18 Siegfried M, Choi KS. Elucidating the effect of additives on the growth and stability of $\mathrm{Cu}_{2} \mathrm{O}$ surfaces via shape transformation of pre-grown crystals. J Am Chem Soc, 2006, 128: 10356-10357

19 Pan Q, Lu L. Dislocation characterization in fatigued $\mathrm{Cu}$ with nanoscale twins. Sci China Mater, 2015, 58: 915-920

20 Lee WR, Lim Y, Kim S, et al. Crystal-to-crystal conversion of $\mathrm{Cu}_{2} \mathrm{O}$ nanoparticles to $\mathrm{Cu}$ crystals and applications in printed electronics. J Mater Chem, 2011, 21: 6928-6933

21 Su J, Zhang J, Liu Y, et al. Parameter-dependent oxidation of physically sputtered $\mathrm{Cu}$ and the related fabrication of $\mathrm{Cu}$-based semiconductor films with metallic resistivity. Sci China Mater, 2016, 59: 144-150

22 Yang C, Xiao F, Wang J, et al. Synthesis and microwave modification of $\mathrm{CuO}$ nanoparticles: crystallinity and morphological variations, catalysis, and gas sensing. J Colloid Interface Sci, 2014, 435: $34-42$

23 Wu F, Cao F, Liu Q, et al. Enhancing photoelectrochemical activity with three-dimensional p-CuO/n- $\mathrm{ZnO}$ junction photocathodes. Sci China Mater, 2016, 59: 825-832

24 Zhang Y, Ji Y, Li J, et al. Morphology-dependent catalytic properties of nanocupric oxides in the Rochow reaction. Nano Res, 2017, 336

$25 \mathrm{Lu} \mathrm{L}$, Wang Y. Sheet-like and fusiform $\mathrm{CuO}$ nanostructures grown on graphene by rapid microwave heating for high Li-ion storage capacities. J Mater Chem, 2011, 21: 17916-17921

26 Zhang Y, Ji Y, Li J, et al. Hierarchical zinc-copper oxide hollow microspheres as active Rochow reaction catalysts: the formation and effect of charge transferable interfaces. J Catal, 2017, 348: 233245

27 Muller R. One hundred years of organosilicon chemistry. J Chem Educ, 1965, 42: 41-45

28 Zhang Z, Che H, Wang Y, et al. Facile solvothermal synthesis of porous cubic $\mathrm{Cu}$ microparticles as copper catalysts for Rochow reaction. ACS Appl Mater Interfaces, 2012, 4: 1295-1302

29 Zhang Z, Che $\mathrm{H}$, Gao J, et al. Shape-controlled synthesis of $\mathrm{Cu}_{2} \mathrm{O}$ microparticles and their catalytic performances in the Rochow reaction. Catal Sci Technol, 2012, 2: 1207-1212

30 Zhang Y, Li J, Liu H, et al. Promoting effect of $\operatorname{In}_{2} \mathrm{O}_{3}$ on $\mathrm{CuO}$ for the Rochow reaction: the formation of $\mathrm{P}-\mathrm{N}$ junctions at the heterointerfaces. J Catal, 2017, 348: 110-124

31 Luo WX, Wang GR, Wang JF, et al. Modification of $\mathrm{CuCl}$ catalyst used in the direct synthesis reaction of methyl chlorosilane monomer. Chem Eng, 2006, 34: 41-44

32 Li J, Zhang Z, Ji Y, et al. One-dimensional Cu-based catalysts with layered $\mathrm{Cu}-\mathrm{Cu}_{2} \mathrm{O}-\mathrm{CuO}$ walls for the Rochow reaction. Nano Res, 2016, 9: 1377-1392

33 Zou S, Ji Y, Li J, et al. Novel leaflike Cu-O-Sn nanosheets as highly efficient catalysts for the Rochow reaction. J Catal, 2016, 337: 1-13

34 Ji Y, Jin Z, Li J, et al. Rambutan-like hierarchically heterostructured $\mathrm{CeO}_{2}-\mathrm{CuO}$ hollow microspheres: facile hydrothermal synthesis and applications. Nano Res, 2017, 10: 381-396

35 Schaub R, Wahlström E, Rønnau A, et al. Oxygen-mediated diffusion of oxygen vacancies on the $\mathrm{TiO}_{2}(110)$ surface. Science, 2003, 
299: 377-379

36 Huang S, Xu Y, Liu Q, et al. Enhancing reactive oxygen species generation and photocatalytic performance via adding oxygen reduction reaction catalysts into the photocatalysts. Appl Catal BEnviron, 2017, 218: 174-185

37 Li Z, Bosman M, Yang Z, et al. Interface and surface cation stoichiometry modified by oxygen vacancies in epitaxial manganite films. Adv Funct Mater, 2012, 22: 4312-4321

38 Bosko S, Moskaleva L, Matveev A, et al. Optical spectra of $\mathrm{Cu}, \mathrm{Ag}$, and $\mathrm{Au}$ monomers and dimers at regular sites and oxygen vacancies of the $\mathrm{MgO}(001)$ surface. A systematic time-dependent density functional study using embedded cluster models. J Phys Chem A, 2007, 111: 6870-6880

39 Lopez N, Illas F, Pacchioni G. Adsorption of $\mathrm{Cu}, \mathrm{Pd}$, and $\mathrm{Cs}$ atoms on regular and defect sites of the $\mathrm{SiO}_{2}$ surface. J Am Chem Soc, 1999, 121: 813-821

40 Tyn M, Calus W. Diffusion coefficients in dilute binary liquid mixtures. J Chem Eng Data, 1975, 20: 106-109

41 Easteal A, Edge A, Woolf L. Isotope effects in water. Tracer diffusion coefficients for water(oxygen-18) (H218O) in ordinary water. J Phys Chem, 1984, 88: 6060-6063

42 Derlacki Z, Easteal A, Edge A, et al. Diffusion coefficients of methanol and water and the mutual diffusion coefficient in methanolwater solutions at 278 and $298 \mathrm{~K}$. J Phys Chem, 1985, 89: 53185322

43 Easteal A, Woolf L. Pressure and temperature dependence of tracer diffusion coefficients of methanol, ethanol, acetonitrile, and formamide in water. J Phys Chem, 1985, 89: 1066-1069

44 Song X, Gao L, Mathur S. Synthesis, characterization, and gas sensing properties of porous nickel oxide nanotubes. J Phys Chem C, 2011, 115: 21730-21735

45 Liu J, Chen X, Wang W, et al. Large scale synthesis of porous ZnO hollow structures with tunable diameters and shell thicknesses. Mater Lett, 2009, 63: 2221-2223

46 Liu S, Wang Y, Zhu Y, et al. Controllably oxidized copper flakes as multicomponent copper-based catalysts for the Rochow reaction. RSC Adv, 2014, 4: 7826-7833
47 Guo Z, Seol ML, Kim MS, et al. Hollow CuO nanospheres uniformly anchored on porous Si nanowires: preparation and their potential use as electrochemical sensors. Nanoscale, 2012, 4: 75257531

48 Zhao W, Zhang C, Geng F, et al. Nanoporous hollow transition metal chalcogenide nanosheets synthesized via the anion-exchange reaction of metal hydroxides with chalcogenide ions. ACS Nano, 2014, 8: 10909-10919

49 Banholzer W. Active site formation in the direct process for methylchlorosilanes. J Catal, 1986, 101: 405-415

50 Wang Z, Jiang S, Li Y, et al. Highly active $\mathrm{CeO}_{2}$ hollow-shell spheres with Al doping. Sci China Mater, 2017, 60: 646-653

51 Chen $\mathrm{C}, \mathrm{Xu} \mathrm{K}$, Ji X, et al. Enhanced electrochemical performance by facile oxygen vacancies from lower valence-state doping for ramsdellite- $\mathrm{MnO}_{2}$. J Mater Chem A, 2015, 3: 12461-12467

52 Yang $\mathrm{Y}$, Zhang S, Wang S, et al. Ball milling synthesized $\mathrm{MnO}_{x}$ as highly active catalyst for gaseous POPs removal: significance of mechanochemically induced oxygen vacancies. Environ Sci Technol, 2015, 49: 4473-4480

Acknowledgements The work was supported by the National Natural Science Foundation of China (21506224). Zhong Z thanks the Institute of Chemical and Engineering Sciences (ICES) for the kind support of the collaboration.

Author contributions Ji Y, Wang X and Su F conceived the idea of the project. Liu $\mathrm{H}$ conducted the synthesis of materials. Liu H, Li J and Zhong Z performed the characterizations and catalytic tests. Ji Y, Wang $\mathrm{X}$ and Su F analyzed the data. Liu J, Ji Y, Wang X, Zhang Z and Su F drafted the manuscript. Liu $\mathrm{H}$ and Li J contributed equally to this work. All authors participated the general discussion of the manuscript.

Conflict of interest The authors declare that they have no conflict of interest.

Supplementary information Experimental details are available in the online version of the paper. 

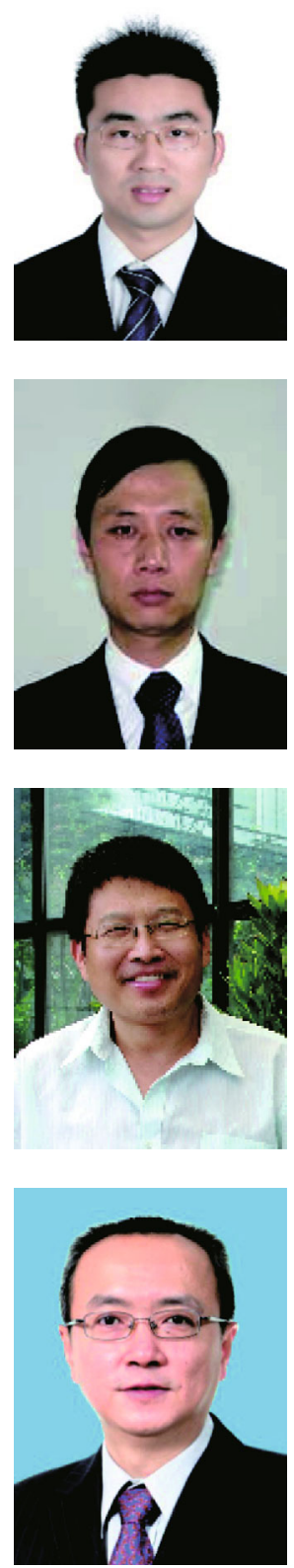

Hezhi Liu received his MSc degree from Shanghai University in 2012. Then, he worked as a research assistant in the group of catalysis and porous materials for energy at the Institute of Process Engineering, Chinese Academy and Sciences (IPE, CAS). Then he joined the State Key Laboratory of Advanced Special Steel at Shanghai University to proceed his PhD degree in 2015. His research focuses on controllable synthesis of catalysis and porous materials applied in energy field.

Yongjun Ji received his BSc degree from Shanxi Normal University in 2004, and PhD degree from East China Normal University in 2012, under the supervision of Prof. Peng Wu. After postdoctoral research at Tsinghua University with Prof. Yadong Li, he joined the faculty of the IPE, CAS in 2014. He is currently an associate professor. His research interests include the synthesis and application of zeolite and nanomaterials.

Xueguang Wang graduated from Shanghai Light Industrial College, received MSc (1996) and PhD degrees (2001) in physical chemistry from Jilin University and Nanjing University, respectively. He worked as a postdoctoral fellow at BenGurion University of Negev in Israel in 2002, Taiwan University from 2003 to 2005, and National Institute of Advanced Industrial Science and Technology (AIST) in Japan from 2006 to 2007. Since 2008, he has been a professor of physical chemistry at Shanghai University. His current research is focused on heterogeneous catalysis, inorganic porous materials, and metal and/or metal oxide nanomaterials.

Fabing Su received his BSc degree from the Department of Chemical Engineering, Tsinghua University in 1991 and MSc degree from the Department of Environmental and Chemical Engineering, Research Institute of Chemical Defense (RICD) in 1994, and PhD degree from the Department of Chemical and Biomolecular Engineering, National University of Singapore in 2005 under the supervision of Prof. Xiusong Zhao. Then, he worked as a research fellow at National University of Singapore in 2006, the University of Liverpool in UK in 2007, and Institute of Chemical and Engineering Sciences (ICES) in Singapore from 2008 to 2009. He joined the faculty of the Institute of Process Engineering, Chinese Academy of Sciences in 2010 as a full professor. His research interests are focused on the synthesis of porous materials for energy storage and conversion, and heterogeneous catalysis.

\section{扩散控制合成Cu基催化剂及其Rochow反应性能研究}

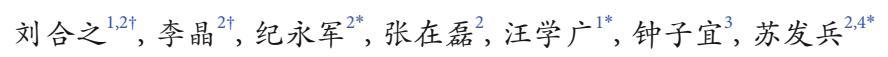

摘要 大多数材料的功能和性质取决于它们的结构, 而扩散机制是调控材料生长和结构的一个主要动力学因素. 本工作提出了一条系统 且可行的策略即通过控制扩散系数来制备 $\mathrm{Cu}_{2} \mathrm{O}$ 固体球和六面体, 且这些 $\mathrm{Cu}_{2} \mathrm{O}$ 产物可以分别通过水合肼溶液中氢原子扩散控制和空气中 氧原子扩散控制, 转变成相应的 $\mathrm{Cu}$ 中空球和六面体, 以及 $\mathrm{CuO}$ 多孔球和六面体. 此外, 对转变过程的微观机制作了详尽的讨论; 用固定床 评价了这些材料在用来合成有机硅行业广泛使用的单体的Rochow反应中的催化性能. 结果表明, 相较于 $\mathrm{Cu}$ 中空球, $\mathrm{Cu}_{2} \mathrm{O}$ 固体球和 $\mathrm{CuO}$ 多 孔球表现出了更高的二甲基二氯硅烷选择性和硅粉原料转化率, 这主要归因于在形成 $\mathrm{Cu}_{x} \mathrm{Si}$ 活性相的过程中, $\mathrm{Cu}_{2} \mathrm{O}$ 和 $\mathrm{CuO}$ 中的晶格氧去除 以后形成的表面氧缺陷可以作为反应物 $\mathrm{CH}_{3} \mathrm{Cl}$ 的吸附活性位. 该工作不仅提出一种制备规整 $\mathrm{Cu}_{2} \mathrm{O}$ 固体球和六面体的可行方法, 而且揭示 了 Rochow反应合成单体二甲基二氯硅烷中 $\mathrm{Cu}, \mathrm{Cu}_{2} \mathrm{O}$ 和 $\mathrm{CuO}$ 各自的催化作用. 